\title{
Alexander S. Galushko • Bernhard Schink \\ Oxidation of acetate through reactions of the citric acid cycle by Geobacter sulfurreducens in pure culture and in syntrophic coculture
}

Received: 19 May 2000 / Revised: 2 August 2000 / Accepted: 3 August 2000 / Published online: 10 October 2000

(C) Springer-Verlag 2000

\begin{abstract}
Geobacter sulfurreducens strain PCA oxidized acetate to $\mathrm{CO}_{2}$ via citric acid cycle reactions during growth with acetate plus fumarate in pure culture, and with acetate plus nitrate in coculture with Wolinella succinogenes. Acetate was activated by succinyl-CoA:acetate CoA-transferase and also via acetate kinase plus phosphotransacetylase. Citrate was formed by citrate synthase. Soluble isocitrate and malate dehydrogenases reduced $\mathrm{NADP}^{+}$and $\mathrm{NAD}^{+}$, respectively. Oxidation of 2-oxoglutarate was measured as benzyl viologen reduction and was strictly CoA-dependent; a low activity was also observed with $\mathrm{NADP}^{+}$. Succinate dehydrogenase and fumarate reductase both were membrane-bound. Succinate oxidation was coupled to $\mathrm{NADP}^{+}$reduction whereas fumarate reduction was coupled to NADPH and NADH oxidation. Coupling of succinate oxidation to $\mathrm{NADP}^{+}$or cytochrome(s) reduction required an ATP-dependent reversed electron transport. Net ATP synthesis proceeded exclusively through electron transport phosphorylation. During fumarate reduction, both NADPH and NADH delivered reducing equivalents into the electron transport chain, which contained a menaquinone. Overall, acetate oxidation with fumarate proceeded through an open loop of citric acid cycle reactions, excluding succinate dehydrogenase, with fumarate reductase as the key reaction for electron delivery, whereas acetate oxidation in the syntrophic coculture required the complete citric acid cycle.
\end{abstract}

Keywords Anaerobic acetate degradation - Reversed electron transport - Fumarate reduction - Syntrophy · Iron-reducing bacteria $\cdot$ Wolinella succinogenes

Abbreviations $C T A B$ Cetyltrimethylammonium bromide - $D C C D N, N$-dicyclohexylcarbodiimide . $H O Q N O$ 2- $n$-Heptyl-4-hydroxyquinoline- $N$-oxide

A. S. Galushko (®) · B. Schink

Fakultät für Biologie, Universität Konstanz, Postfach 5560, 78457 Konstanz, Germany

e-mail: alexander.galushko@uni-konstanz.de,

Tel.: +49-7531-883558, Fax: +49-7531-882966

\section{Introduction}

Geobacter sulfurreducens strain PCA is a mesophilic freshwater bacterium that can grow by acetate oxidation coupled to reduction of $\mathrm{Fe}(\mathrm{III})$, elemental sulfur, or fumarate as electron acceptor (Caccavo et al. 1994). It can also grow on acetate, releasing electrons via interspecies electron transfer to Wolinella succinogenes or Desulfovibrio desulfuricans, with nitrate as terminal electron acceptor (Cord-Ruwisch et al. 1998). Previously described syntrophic acetate-degrading cocultures are either thermophilic or mesophilic and couple to methanogenic (Zinder and Koch 1984; Schnürer et al. 1994; Hattori et al. 2000) or sulfidogenic (Galouchko and Rozanova 1996) partners. All these cultures grow very slowly, with doubling times of several days.

Two main pathways for acetate oxidation by anaerobic bacteria are known: the $\mathrm{CO}$ dehydrogenase/acetyl-CoA pathway and the citric acid cycle, with either CO dehydrogenase/acetyl-CoA synthase or 2-oxoglutarate:electron acceptor oxidoreductase as the key enzymes, respectively (Thauer 1988; Ragsdale 1991). The CO dehydrogenase pathway is more likely to operate in syntrophic acetate-oxidizing cocultures if electrons are transferred between the partners in the form of hydrogen or formate (Thauer 1988; Schink 1997) because the average redox potential of the oxidation steps in this pathway $(-339 \mathrm{mV})$ is closer to that of the proton/hydrogen couple $(-414 \mathrm{mV})$ than to that of the oxidation steps in the citric acid cycle $(-247 \mathrm{mV}$; all redox potential values given for $\mathrm{pH} 7.0$; Thauer 1988), meaning that the former pathway operates closer to the thermodynamic equilibrium than the latter one does. Indeed, the acetate-degrading partners in the thermophilic and mesophilic methanogenic cocultures are homoacetogenic bacteria capable of acetate oxidation or acetate synthesis via the $\mathrm{CO}$ dehydrogenase pathway (Lee and Zinder 1988a, b; Schnürer et al. 1996, 1997). The direction of acetate metabolism in these bacteria strongly depends on the hydrogen partial pressure. In the case of G. sulfurreducens, some preliminary data indicated that 
the mechanism of syntrophic acetate oxidation could be different. Bacteria that are closely related to G. sulfurreducens on the basis of 16S rRNA sequence analysis (Desulfuromonas acetoxidans, G. metallireducens and G. sulfurreducens strain AM-1) oxidize acetate through the citric acid cycle (Gebhardt et al. 1985; Champine and Goodwin 1991; Mikoulinskaia et al. 1999; Champine et al. 2000). Moreover, it has been suggested that electrons could be delivered to W. succinogenes through a carrier system with a redox potential higher than that of the proton/hydrogen couple (Cord-Ruwisch et al. 1998; Seeliger et al. 1998). In particular, if a cytochrome with a standard redox potential of $-167 \mathrm{mV}$ is involved in interspecies electron transfer, this could make acetate oxidation through the citric acid cycle reactions feasible.

In this article, we report that $G$. sulfurreducens strain PCA degrades acetate through citric acid cycle reactions during growth on acetate plus fumarate and also in coculture with $W$. succinogenes on acetate plus nitrate.

\section{Materials and methods}

Bacteria and growth conditions

Geobacter sulfurreducens strain PCA (DSM 12127; ATCC 51573) was obtained from R. Cord-Ruwisch (Perth, Australia), and Wolinella succinogenes DSM 1740 was provided by A. Kröger (Frankfurt, Germany).

Bacteria were cultivated in a bicarbonate $/ \mathrm{CO}_{2}$-buffered, cysteine-reduced medium for freshwater bacteria (Cord-Ruwisch et al. 1998; Seeliger et al. 1998). For enzyme activity measurements and determination of growth parameters, G. sulfurreducens was routinely cultivated in this medium with $20 \mathrm{mM}$ acetate plus $40 \mathrm{mM}$ fumarate. A coculture of $G$. sulfurreducens and W. succinogenes was grown with $10 \mathrm{mM}$ each of acetate and nitrate (Cord-Ruwisch et al. 1998). W. succinogenes grew in the same medium with $30 \mathrm{mM}$ formate plus $10 \mathrm{mM}$ nitrate. Growth substrates were added from anoxic, sterile stock solutions by syringes flushed with $\mathrm{N}_{2} / \mathrm{CO}_{2}(80: 20$, v/v).

\section{Preparation of cell extracts}

Geobacter sulfurreducens was grown in 11 medium (in 1.2-1 infusion bottles) under an $\mathrm{N}_{2} / \mathrm{CO}_{2}(80: 20, \mathrm{v} / \mathrm{v})$ gas phase. Cells were harvested in the late exponential growth phase by centrifugation for $20 \mathrm{~min}$ at $10,000 \times g$ under anoxic conditions. The cell pellet was suspended in $50 \mathrm{ml}$ of anoxic $50 \mathrm{mM}$ potassium phosphate buffer, $\mathrm{pH} 7.3$, containing $2.5 \mathrm{mM} \mathrm{MgCl}_{2}$ and $2.5 \mathrm{mM}$ dithiothreitol, and centrifuged again as described above. Harvested cells were resuspended in $2.5 \mathrm{ml}$ of the same buffer and passed two to three times through an anoxic French press cell at $137 \mathrm{MPa}$. Cell debris and intact cells were removed from the homogenate by centrifugation $(20 \mathrm{~min}$ at $30,000 \times \mathrm{g})$. The membrane fraction was separated from the soluble fraction by ultracentrifugation for $1 \mathrm{~h}$ at $125,000 \times g$. Fractions were transferred into small glass vials under an $\mathrm{N}_{2}$ atmosphere and stored on ice. Enzyme activities were measured within $1-8 \mathrm{~h}$ after preparation.

All manipulations of cells were performed in an anoxic chamber (Coy Laboratory Products, Ann Arbor, Mich.) under $\mathrm{N}_{2} / \mathrm{H}_{2}$ atmosphere $(95 / 5, \mathrm{v} / \mathrm{v})$.

Enzyme assays

Enzyme activities were measured photometrically at $30^{\circ} \mathrm{C}$ under an $\mathrm{N}_{2}$ atmosphere (unless otherwise indicated) in glass cuvettes
(1 ml assay mixture) sealed with butyl rubber stoppers. Anoxic conditions were achieved by flushing cuvettes with $\mathrm{N}_{2}$.

Acetate kinase and phosphotransacetylase were assayed according to Bergmeyer (1983). Citric acid cycle enzymes (citrate synthase, ATP-citrate lyase, aconitase, isocitrate dehydrogenase, 2-oxoglutarate:electron acceptor oxidoreductase, succinyl-CoA synthetase, succinyl-CoA:acetate CoA-transferase, succinate dehydrogenase, fumarate reductase, fumarase) were determined according to described procedures (Brandis-Heep et al. 1983; Stams et al. 1984; Möller et al. 1987; Beh et al. 1993). Malate dehydrogenase activity was assayed in the direction of oxaloacetate reduction following the decrease of NADH or NADPH absorption at $365 \mathrm{~nm}$. In addition, malate oxidation was studied by following $\mathrm{NAD}^{+}$or NADP ${ }^{+}$reduction in the presence or absence of $0.2 \mathrm{mM}$ acetyl-CoA. The assay mixture contained $50 \mathrm{mM}$ potassium phosphate buffer, $\mathrm{pH}$ 7.0, $5 \mathrm{mM}$ malate, and $0.4 \mathrm{mM} \mathrm{NAD}^{+}$or $\mathrm{NADP}^{+}$. ATP-driven succinate oxidation coupled to $\mathrm{NAD}^{+}$or $\mathrm{NADP}^{+}$reduction, the effect of $N, N$-dicyclohexylcarbodiimide (DCCD) on the reaction, and fumarate reduction with NADH or NADPH were determined as described (Paulsen et al. 1986).

Formate dehydrogenase, $\mathrm{CO}$ dehydrogenase, and hydrogenase were assayed as benzyl viologen $(2 \mathrm{mM})$ reduction in the presence of the respective substrates (Zeikus et al. 1977). Carbon monoxide and hydrogen were supplied in the gas phase and the buffer used was saturated with these gases in advance. Formate dehydrogenase was tested with $10 \mathrm{mM}$ formate under $100 \% \mathrm{~N}_{2}$ gas phase.

Reduction of cytochrome(s) of G. sulfurreducens present in cell-free extract by intermediates of the citric acid cycle (isocitrate, 2-oxoglutarate, succinate, malate), NADH, or NADPH was determined by measuring absorption changes at $553 \mathrm{~nm}$ after addition of the respective electron donors $\left(\varepsilon=31.4 \mathrm{mM}^{-1} \mathrm{~cm}^{-1}\right)$. Cell-free extract was prepared in anoxic $50 \mathrm{mM}$ potassium phosphate buffer, $\mathrm{pH} 7.0$, without a reducing agent. The assay volume was $1.0 \mathrm{ml}$ and contained $850 \mu \mathrm{l}$ buffer and $100 \mu \mathrm{l}$ extract. Before starting the reaction, by addition of $50 \mu \mathrm{l}$ of electron donor from anoxic stock solutions, cytochrome(s) were oxidized by shaking the cuvettes after supplying 10-30 $\mu \mathrm{l}$ air to the gas phase.

\section{Analytical procedures}

The content of organic acids in the growth medium was measured by HPLC with a Bio-Rad Aminex HPX-87H column $(300 \times 7.8$ $\mathrm{mm}$ ). Samples were eluted with $5 \mathrm{mM} \mathrm{H}_{2} \mathrm{SO}_{4}$ in water (flow rate

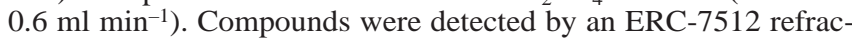
tion index detector (Erma).

Growth of $G$. sulfurreducens was followed by measuring the optical density at $660 \mathrm{~nm}$ in a $1-\mathrm{ml}$ cuvette with a $1-\mathrm{cm}$ light path. Cell dry mass was calculated via an experimentally determined conversion factor $(1 \mathrm{OD}$ at $660 \mathrm{~nm}$ of culture grown on acetate plus fumarate mixture corresponded to $340 \mathrm{mg}$ cellular protein $\mathrm{l}^{-1}$ ). Acetate consumption for cell mass synthesis was calculated according to the equation:

$$
17 \mathrm{CH}_{3} \mathrm{COO}^{-}+11 \mathrm{H}_{2} \mathrm{O} \rightarrow 8\left\langle\mathrm{C}_{4} \mathrm{H}_{7} \mathrm{O}_{3}\right\rangle+2 \mathrm{HCO}_{3}{ }^{-}+15 \mathrm{OH}^{-}
$$

Extraction of menaquinone followed a described procedure (Shestopalov et al. 1997). Menaquinones were detected by their UV absorption spectra at 200-350 nm with an Uvikon-930 spectrophotometer (Kontron Instruments). Vitamin $\mathrm{K}_{1}$ was used as a reference.

Protein content in cell extracts and cell suspensions was measured with bicinchoninic acid according to a standard and an enhanced protocol, respectively, (BCA protein assay kit; Pierce). Bovine serum albumin fraction $\mathrm{V}$ (Pierce) was used for calibration.

\section{Chemicals and gases}

All chemicals were of analytical or reagent grade quality and were obtained from Biomol (Ilvesheim, Germany), Boehringer (Mannheim, Germany), Fluka (Neu-Ulm, Germany), Merck (Darmstadt, 
Germany), Serva (Heidelberg, Germany), and Sigma (Deisenhofen, Germany). Gases were purchased from Messer-Griesheim (Darmstadt, Germany), and Sauerstoffwerke Friedrichshafen (Friedrichshafen, Germany).

\section{Results}

Acetate oxidation in pure culture

Geobacter sulfurreducens strain PCA grew in batch culture on acetate plus fumarate with an average doubling time of $7.7 \mathrm{~h}\left(\mu=2.2\right.$ day $\left.^{-1}\right)$ (Fig. 1). Up to $5 \mathrm{mM}$ malate accumulated transiently in the medium during growth. The bacteria reduced $4.05 \mathrm{~mol}$ fumarate per $1 \mathrm{~mol}$ acetate dissimilated (Table 1). The ratio of fumarate metabolized over succinate produced was very close to $1(0.98-0.99)$, indicating only an insignificant contribution of these compounds to cell matter formation. Around $46 \%$ of metabolized acetate was assimilated. The biomass produced was proportional to the amount of acetate dissimilated, with a yield of $42 \mathrm{~g}$ cell dry mass per mol acetate. During growth, the rate of dissimilatory acetate oxidation was around $70 \mathrm{nmol} \mathrm{min}^{-1}(\mathrm{mg} \text { protein })^{-1}$. When the bacterium was cultivated in medium with excess fumarate $(10 \mathrm{mM}$ acetate plus $50 \mathrm{mM}$ fumarate), growth stopped after depletion of acetate.

High specific activities of acetate kinase and phosphotransacetylase (Table 2) demonstrated that acetate could be activated through acetyl phosphate, coupled to hydrolysis of 1 ATP per acetate. Extracts also had substantial succinyl-CoA:acetate CoA-transferase activity. AcetylCoA synthetase was not found.

Cell extracts of $G$. sulfurreducens contained all enzymes required for acetate oxidation through citric acid cycle reactions (Table 2). Enzymes dealing with fumarate reduction or succinate oxidation were the only ones found in the membrane fraction. Fumarate reduction by reduced benzyl viologen was stimulated 13 -fold in cells permeabilized with cetyltrimethylammonium bromide (CTAB) in comparison to non-permeabilized cells (data not shown).

Citrate synthesis from oxaloacetate and acetyl-CoA in cell-free extracts did not depend on the presence of ADP plus inorganic phosphate. Isocitrate dehydrogenase was strictly $\mathrm{NADP}^{+}$-dependent. Oxidation of 2-oxoglutarate, measured as benzyl viologen reduction, was strictly CoAdependent (Tables 2,3); a low activity was also observed with $\mathrm{NADP}^{+}$but not with $\mathrm{NAD}^{+}$. Succinyl-CoA synthetase was absent and succinate was released only in a transferase reaction with acetate as CoA-acceptor.
Fig. 1 Growth of Geobacter sulfurreducens on acetate plus fumarate. Time course of changes in concentrations of acetate $(\mathbf{\Delta})$, fumarate $(\boldsymbol{\bullet})$, succinate $(\bullet)$ and malate $(\boldsymbol{\square})$. Growth is shown as the change in optical density of the culture at $660 \mathrm{~nm}(\square)$. Acetate concentration changes shown represent the total acetate consumption including dissimilation $(54 \%)$ and assimilation $(46 \%)$

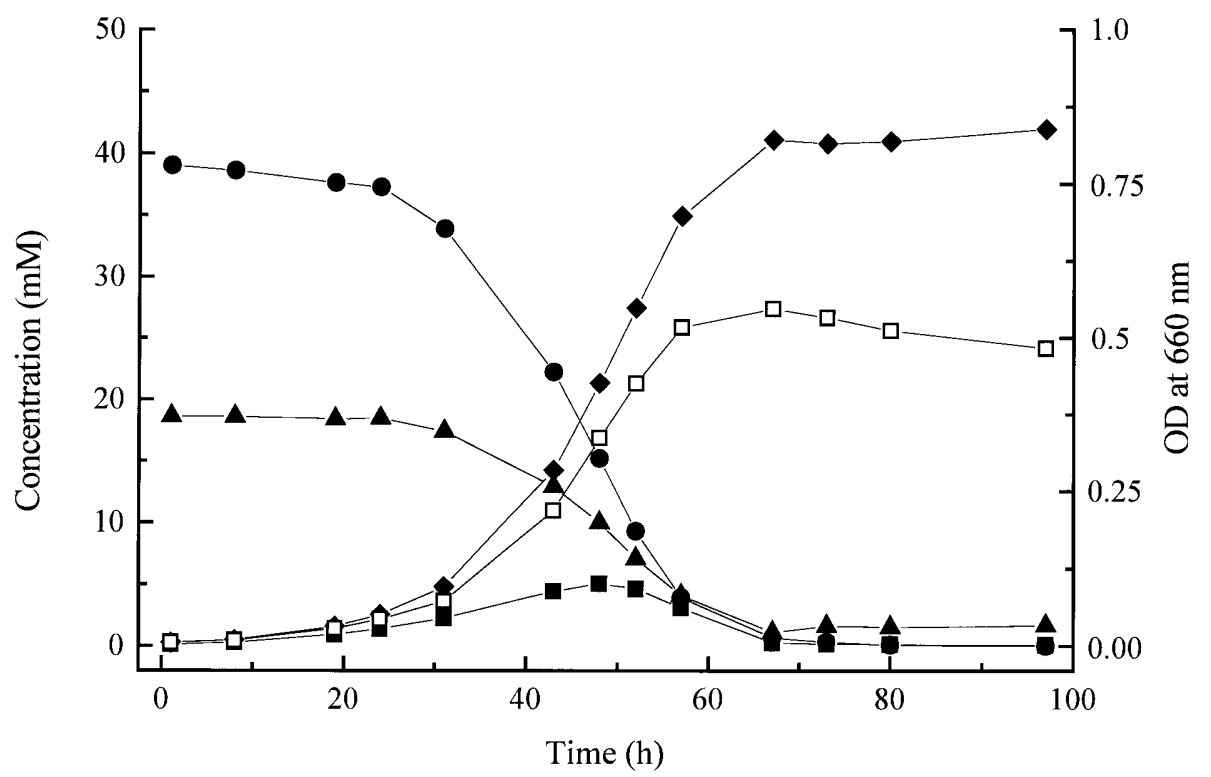

Table 1 Quantification of acetate consumption, fumarate reduction, and growth of Geobacter sulfurreducens

\begin{tabular}{|c|c|c|c|c|c|}
\hline \multicolumn{2}{|c|}{ Substrate consumed (mM) } & \multirow{2}{*}{$\begin{array}{l}\text { Acetate dissimilated } \\
(\mathrm{mM})^{\mathrm{b}}\end{array}$} & \multirow{2}{*}{$\begin{array}{l}\text { Succinate produced } \\
(\mathrm{mM})\end{array}$} & \multirow{2}{*}{$\begin{array}{l}\text { Cell dry mass formed } \\
\left(\mathrm{mg} \mathrm{l}^{-1}\right)\end{array}$} & \multirow{2}{*}{$\begin{array}{l}\text { Electron recovery } \\
(\%)^{\mathrm{c}}\end{array}$} \\
\hline Acetate & Fumarate $^{\mathrm{a}}$ & & & & \\
\hline 10.00 & 21.65 & 5.32 & 21.78 & 227 & 102 \\
\hline 15.00 & 32.99 & 8.10 & 33.72 & 334 & 104 \\
\hline
\end{tabular}

${ }^{a}$ Calculated as change of fumarate plus malate concentrations

${ }^{b}$ The difference between acetate consumed and acetate used for cell synthesis was calculated from the assimilation equation given in the Methods section
${ }^{\mathrm{c}}$ Amount of electrons found in produced succinate compared with amount of electrons derived from dissimilated acetate 
Table 2 Enzymes involved in acetate activation and oxidation in cell-free extracts of $G$. sulfurreducens grown on acetate plus fumarate. The acetate dissimilation rate was $70 \mathrm{nmol} \mathrm{min}^{-1}$ (mg protein $)^{-1}$. nd Not determined

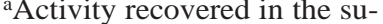
pernatant after ultracentrifugation $(1 \mathrm{~h}$ at $125,000 \times \mathrm{g})$ expressed as percentage of total activity in cell-free extract

\begin{tabular}{|c|c|c|}
\hline Enzymes & $\begin{array}{l}\text { Specific activity } \\
{\left[\mathrm{nmol} \mathrm{min}^{-1}\right.} \\
\left.(\mathrm{mg} \text { protein })^{-1}\right]\end{array}$ & $\begin{array}{l}\text { Activity in soluble fraction } \\
(\% \text { of total activity })^{\mathrm{a}}\end{array}$ \\
\hline \multicolumn{3}{|l|}{ Acetate activation } \\
\hline Acetate kinase & 280 & 105 \\
\hline Phosphotransacetylase & 4470 & 117 \\
\hline \multicolumn{3}{|l|}{ Citric acid cycle } \\
\hline Citrate synthase & 860 & 95 \\
\hline Aconitase & 240 & 102 \\
\hline $\begin{array}{l}\text { Isocitrate dehydrogenase } \\
\text { (NADP }{ }^{+} \text {-dependent) }\end{array}$ & 700 & 99 \\
\hline \multicolumn{3}{|l|}{ 2-Oxoglutarate:acceptor oxidoreductase } \\
\hline benzyl viologen reduction & 420 & 105 \\
\hline $\mathrm{NADP}^{+}$reduction & 5 & nd \\
\hline Succinyl CoA:acetate CoA transferase & 900 & 84 \\
\hline \multicolumn{3}{|l|}{ Succinate dehydrogenase } \\
\hline ferricyanide reduction & 40 & 4 \\
\hline $\mathrm{NADP}^{+}$reduction (plus ATP) & 100 & nd \\
\hline \multicolumn{3}{|l|}{ Fumarate reductase } \\
\hline NADPH-dependent & 540 & 0.1 \\
\hline NADH-dependent & 80 & 0.1 \\
\hline Fumarase & 1750 & 120 \\
\hline \multicolumn{3}{|l|}{ Malate dehydrogenase } \\
\hline $\mathrm{NADP}^{+}$-dependent & 1090 & 105 \\
\hline $\mathrm{NAD}^{+}$-dependent & 3680 & 93 \\
\hline
\end{tabular}

Table 3 Key enzymes of acetate oxidation in cell-free extracts of Geobacter sulfurreducens, Wolinella succinogenes, and of the coculture

\begin{tabular}{|c|c|c|c|}
\hline \multirow[t]{2}{*}{ Enzymes } & \multicolumn{3}{|c|}{ Specific activity $\left[\mathrm{nmol} \mathrm{min}^{-1}(\mathrm{mg} \text { protein })^{-1}\right]$} \\
\hline & G. sulfurreducens ${ }^{\mathrm{a}}$ & W. succinogenes ${ }^{\mathrm{b}}$ & Coculture $^{c}$ \\
\hline 2-Oxoglutarate:benzyl viologen oxidoreductase & 420 & 30 & 160 \\
\hline CO dehydrogenase & 60 & 20 & 20 \\
\hline Hydrogenase & 450 & 2 & 0 \\
\hline Formate dehydrogenase & 7 & 3480 & 1320 \\
\hline NADH dehydrogenase & 8 & 850 & 130 \\
\hline NADPH dehydrogenase & 540 & 1350 & 1800 \\
\hline
\end{tabular}

${ }^{\mathrm{a}}$ G. sulfurreducens was grown on acetate plus fumarate

${ }^{\mathrm{b}}$ W. succinogenes was grown on formate plus nitrate

Membranes of $G$. sulfurreducens reduced fumarate with NADPH at a rate higher than with NADH [190 vs 70 nmol $\mathrm{min}^{-1}$ (mg protein) $)^{-1}$, respectively]. The reaction was sensitive to 2- $n$-heptyl-4-hydroxyquinoline- $N$-oxide (HOQNO), a menaquinol analogue (Rothery and Weiner 1998). The presence of $0.5 \mathrm{mM}$ HOQNO in the assay caused a $98.8 \%$ decrease of the fumarate reduction rate. In the reverse direction, the reaction was strictly $\mathrm{NADP}^{+}$-dependent. Membranes reduced $\mathrm{NADP}^{+}$with succinate only in the presence of ATP. The dependence of succinate oxidation on ATP hydrolysis was proven in experiments with DCCD: the rate of ATP-dependent succinate oxidation was decreased by $90 \%$ after incubation of membranes with $125 \mu \mathrm{mol}$ DCCD (mg protein) $)^{-1}$ for $20 \mathrm{~min}$ at $30^{\circ} \mathrm{C}$. This reagent inhibits ATP synthases due to a reaction with
${ }^{\mathrm{c} C o c u l t u r e}$ of $G$. sulfurreducens and $W$. succinogenes was grown on acetate plus nitrate

specific amino acid carboxyl residues (Kluge and Dimroth 1993).

Cell-free extracts always possessed high fumarase activity $\left[3.7 \mu \mathrm{mol} \mathrm{min}^{-1}(\mathrm{mg} \text { protein })^{-1}\right]$. The malate produced was dehydrogenated to oxaloacetate by malate dehydrogenase. Since the standard redox potential of the oxaloacetate/malate couple $(-166 \mathrm{mV})$ is higher than that of possible electron carriers $\left(\mathrm{NAD}(\mathrm{P})^{+} / \mathrm{NAD}(\mathrm{P}) \mathrm{H}\right)$, this reaction is often measured in the thermodynamically favorable direction of oxaloacetate reduction to malate. Under such conditions, malate dehydrogenase activity was found with both NADH and NADPH. However, the activity with NADH was about three times as high as with NADPH (Table 2). Malate oxidation could only be coupled to $\mathrm{NADP}^{+}$reduction at a considerably lower rate [34 


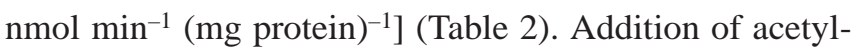
CoA caused a complete loss of this activity, which is characteristic for some $\mathrm{NADP}^{+}$-dependent dehydrogenases decarboxylating malate to pyruvate (malic enzymes; Voegele et al. 1999). In contrast to the $\mathrm{NADP}^{+}$-dependent enzyme, the presence of an $\mathrm{NAD}^{+}$-reducing malate dehydrogenase that operates in the oxidative direction [220 nmol $\min ^{-1}$ (mg protein $)^{-1}$ ] could only be revealed after addition of acetyl-CoA to scavenge oxaloacetate in the exergonic reaction of citrate formation.

While a low activity of $\mathrm{CO}$ oxidation was always detected (Table 3), the even lower activity of formate dehydrogenase (another typical enzyme of the CO/acetyl-CoA pathway) allowed us to conclude that this pathway does not operate in G. sulfurreducens. Growth and cell suspension experiments confirmed that this bacterium could not perform a homoacetogenic metabolism: it did not grow on formate $(40 \mathrm{mM})$, on $\mathrm{H}_{2} / \mathrm{CO}_{2}(80 / 20 \mathrm{vol} \%)$, or $\mathrm{H}_{2} / \mathrm{CO}_{2}$ plus formate. Having active hydrogenase but not formate dehydrogenase (Table 3), it could use hydrogen but not formate for fumarate reduction (data not shown). G. sulfurreducens did not grow on CO (1-10 vol\% in anoxic gas phase) and could not use this substrate as electron donor for fumarate reduction.

The UV spectrum of lipid extract of G. sulfurreducens at $230-350 \mathrm{~nm}$ strongly resembled that of vitamin $\mathrm{K}_{1}$ (data not shown), indicating that it possesses a menaquinone.

Oxidation of acetate by G. sulfurreducens in coculture with $W$. succinogenes

Cocultures of G. sulfurreducens and W. succinogenes grew on acetate as electron donor and nitrate as electron acceptor, with an average doubling time of $5.1 \mathrm{~h}\left(\mu=3.3\right.$ day $\left.^{-1}\right)$. Small amounts of succinate $(30-50 \mu \mathrm{M})$ accumulated in the medium during the stationary phase under nitrate-limiting conditions.

To check how acetate was degraded by cocultures of G. sulfurreducens and W. succinogenes, several enzyme activities in cell-free extracts of the coculture were compared with those of pure cultures of the partner bacteria (Table 3). Coculture extracts had significant 2-oxoglutarate:benzyl viologen oxidoreductase activity. Extracts of $W$. succinogenes exhibited only low activity of this enzyme. Both strains grown in pure cultures and in coculture showed very low CO dehydrogenase activity in cellfree extracts.

Surprisingly, the hydrogenase activity found in cells of G. sulfurreducens grown on acetate plus fumarate was not detectable in the coculture (Table 3). On the contrary, the coculture possessed very high formate dehydrogenase activity which, however, could have originated from cells of $W$. succinogenes. All checked extracts had higher activities of NADPH oxidation than of NADH oxidation (measured as potassium ferricyanide reduction).

Since it was proposed that $c$-type cytochrome(s) could play a significant role as an electron carrier system in the
Table 4 Reduction of cytochrome(s) in cell extracts of G. sulfurreducens by citric acid cycle intermediates and reduced pyridine nucleotides (concentration in assays 5 and $0.5 \mathrm{mM}$, respectively). Protein content in $1 \mathrm{ml}$ assay was $2.6 \mathrm{mg}$

\begin{tabular}{|c|c|}
\hline Substrate & $\begin{array}{l}\text { Specific activity } \\
{\left[\mu \mathrm{mol} \mathrm{min}^{-1}(\mathrm{mg} \text { protein })^{-1}\right]}\end{array}$ \\
\hline Isocitrate & 3.13 \\
\hline 2-Oxoglutarate & 2.72 \\
\hline Succinate & 0.17 \\
\hline Succinate+ATPa & 0.36 \\
\hline Malate & 3.16 \\
\hline NADPH & 2.49 \\
\hline NADH & 0.18 \\
\hline
\end{tabular}

${ }^{\mathrm{a}} 0.1 \mathrm{mM}$ ATP in assay mixture

coculture, we checked the ability of some intermediates of the citric acid cycle, NADPH, and NADH, to serve as electron donors for cytochrome(s) reduction in cell-free extracts of $G$. sulfurreducens. Before assaying, cytochrome(s) were oxidized by addition of a small amount of air. Succinate and NADH showed the lowest rates of cytochrome(s) reduction while the highest ones were caused by isocitrate, 2-oxoglutarate, malate, and NADPH (Table 4). Addition of ATP to the assay mixture stimulated cytochrome reduction by succinate. In contrast, fumarate (concentration in assay $0.25 \mathrm{mM}$ ) oxidized dithionite-reduced cytochrome(s) at a rate of $1.7 \mu \mathrm{mol} \mathrm{\textrm {min } ^ { - 1 }}$ $(\mathrm{mg} \text { protein })^{-1}$.

\section{Discussion}

Geobacter sulfurreducens grows by acetate oxidation coupled to reduction of fumarate to succinate, according to the following equation $\left(\Delta G^{\circ \prime}\right.$ value calculated after Thauer et al. 1977):

$\mathrm{CH}_{3} \mathrm{COO}^{-}+4 \mathrm{C}_{4} \mathrm{H}_{2} \mathrm{O}_{4}^{2-}+2 \mathrm{H}_{2} \mathrm{O}+\mathrm{H}^{+} \rightarrow 2 \mathrm{CO}_{2}+4 \mathrm{C}_{4} \mathrm{H}_{4} \mathrm{O}_{4}{ }^{2-}$ $\Delta G^{\circ \prime}=-249 \mathrm{~kJ}$ per mol acetate

Acetate metabolism proceeds via reactions of the citric acid cycle - all detected enzyme activities were sufficiently high to allow the observed rate of acetate oxidation.

In general, the citric acid cycle reactions found in $G$. sulfurreducens resemble those described for $D$. acetoxidans (Gebhardt et al. 1985). The most remarkable features of this cycle are the formation of citrate via citrate synthase rather than ATP-citrate lyase, and the presence of succinyl-CoA:acetate CoA-transferase instead of succinyl-CoA synthetase. However, the two pathways differ in ATP-dependent succinate oxidation: the reaction in $D$. acetoxidans is coupled to $\mathrm{NAD}^{+}$reduction (Paulsen et al. 1986), whereas in G. sulfurreducens it is coupled to $\mathrm{NADP}^{+}$reduction. Also, the enzyme acting in the backwards direction, fumarate reductase, is membrane-bound and reacts with both NADPH and NADH. Increased fumarate reductase activity in CTAB-permeabilized cell sus- 

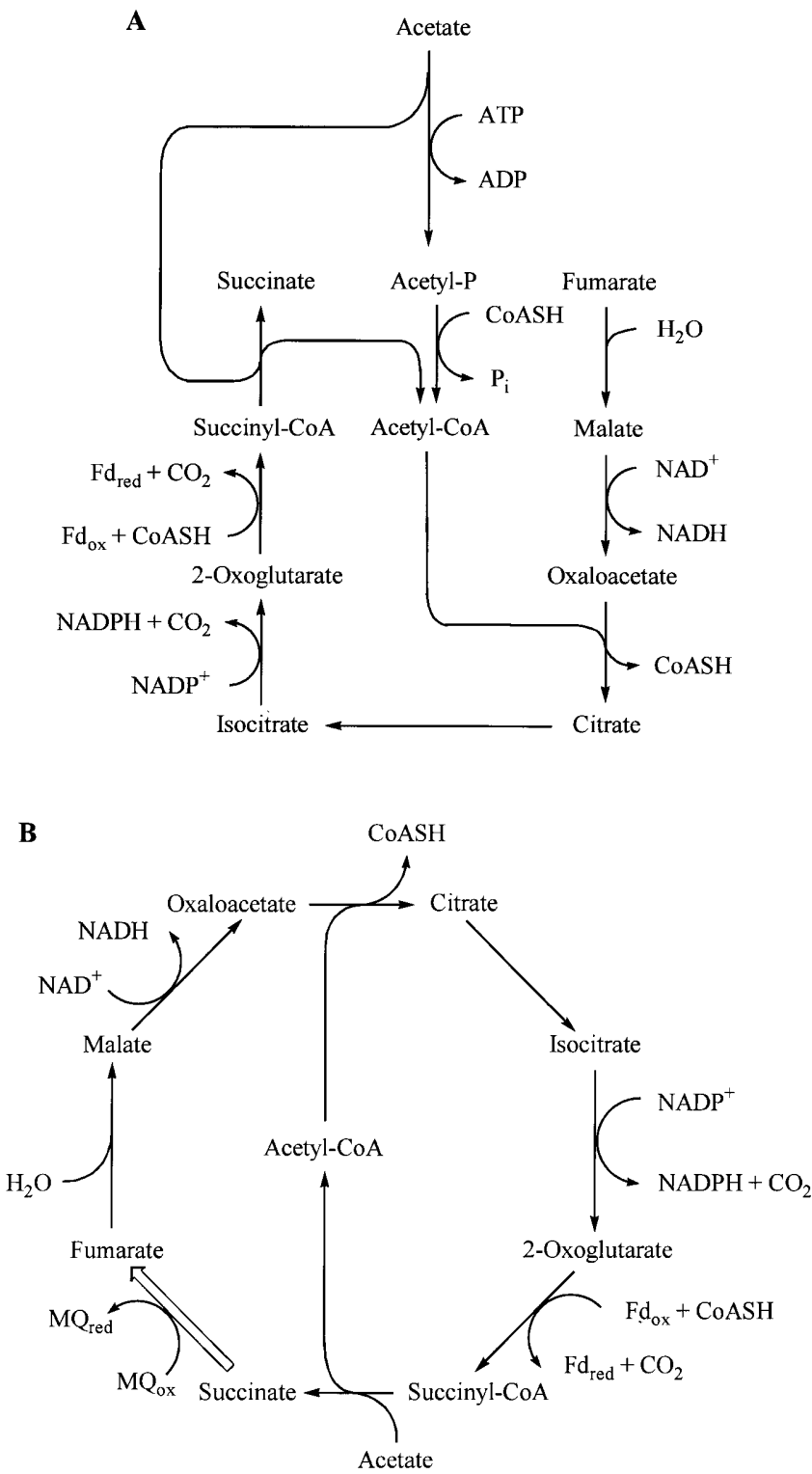

Fig. 2 Pathway of acetate oxidation to $\mathrm{CO}_{2}$ in $G$. sulfurreducens A during growth in pure culture on acetate plus fumarate and B during growth on acetate in coculture with Wolinella succinogenes. The broad arrow refers to membrane-bound succinate dehydrogenase. Ferredoxin is assumed to be the physiological electron acceptor in 2-oxoglutarate oxidation

pensions of G. sulfurreducens indicates that this enzyme is localized at the inner face of the cytoplasmic membrane, as is found in W. succinogenes and Escherichia coli (Kröger et al. 1992; Unden and Bongaerts 1997). In the iron-reducing bacterium Shewanella putrefaciens, fumarate reductase has been described as a soluble, periplasmic flavocytochrome $c$ enzyme (Pealing et al. 1992).

CoA-dependent 2-oxoglutarate oxidation was measured as benzyl viologen reduction, indicating that in vivo this enzyme couples to ferredoxin reduction. Ferredoxin often serves as physiological electron acceptor in this step in sulfate- and sulfur-reducing bacteria (Brandis-Heep et al. 1983; Gebhardt et al. 1985).
Malate oxidation coupled to $\mathrm{NAD}^{+}$reduction is an endergonic process at standard concentrations (standard free energy of the reaction at $\mathrm{pH} 7$ is around $+30 \mathrm{~kJ}$ per mol malate). To overcome this limitation, G. sulfurreducens accumulates malate and keeps the concentration of the reaction product, oxaloacetate, low by efficient removal in the citrate synthase reaction. Malate accumulation is indicated by transient malate release into the medium.

The importance of maintaining a certain intracellular acetyl-CoA level for growth and survival has been proven (Chohnan et al. 1997; Chang et al. 1999). Acetate-degrading anaerobic bacteria often use only one pathway of acetyl-CoA formation (Brandis-Heep et al. 1983; Schmitz et al. 1990), whereas G. sulfurreducens possesses two, thus securing a sufficient flux of acetyl-CoA for assimilatory and dissimilatory metabolism. In addition, minor amounts of acetyl-CoA could be formed also from malate via pyruvate in anaplerotic reactions, including decarboxylating $\mathrm{NADP}^{+}$-dependent malate dehydrogenase and CoA-dependent pyruvate:electron acceptor oxidoreductase; the activity of the latter enzyme was low [20 nmol $\left.\min ^{-1}(\mathrm{mg} \text { protein })^{-1}\right]$. However, the decarboxylating $\mathrm{NADP}^{+}$-dependent malate dehydrogenase is active only at low acetyl-CoA concentrations due to its observed inhibition by acetyl-CoA, and, therefore, cannot sustain growth on fumarate or DL-malate alone in the absence of acetate.

Our results indicate that in this pathway there is no net ATP synthesis through substrate-level phosphorylation, and all ATP has to be produced by electron transport phosphorylation coupled to fumarate reduction. Oxidation of the acetyl residue releases three electron pairs that are transferred to fumarate: two at the redox potential of the $\mathrm{NAD}(\mathrm{P})^{+} / \mathrm{NAD}(\mathrm{P}) \mathrm{H}$ couple, and, presumably, one at that of ferredoxin. The latter one may be further used for $\mathrm{NADP}^{+}$reduction by ferredoxin:NADP ${ }^{+}$oxidoreductase. The presence of such an enzyme in G. sulfurreducens is postulated from the observed $\mathrm{NADP}^{+}$reduction during 2-oxoglutarate oxidation (Table 2). During growth on acetate plus fumarate, succinate is not oxidized to fumarate but excreted into the medium. Oxaloacetate, a substrate for the citrate synthase reaction with acetyl-CoA, is formed from exogenous fumarate via fumarase and malate dehydrogenase. Thus, the pathway does not operate in a cyclic mode but as an open loop (Gottschalk and Andreesen 1979; Fig. 2A).

The electron transport system of $G$. sulfurreducens consists of multiple cytochromes $c$ (Gaspard et al. 1998; Seeliger et al. 1998; Lloyd et al. 1999) plus menaquinone. Menaquinone was detected in the present study, and its involvement in electron transport to fumarate is further supported by the observed inhibition of NADPH oxidation with fumarate by HOQNO, which blocks menaquinolbinding sites of fumarate reductase (Rothery and Weiner 1998). Therefore, we assume that during growth on acetate plus fumarate a menaquinone mediates the transfer of reducing equivalents from pyridine nucleotides further on in the electron transport chain. Redox properties of the chain components have not been evaluated yet. So far 
there is no evidence for the presence of a $b$-type cytochrome in G. sulfurreducens.

Oxidation of $\mathrm{NAD}(\mathrm{P}) \mathrm{H}$ and reduced ferredoxin with ubiquinone via NADH dehydrogenase in aerobic bacteria is coupled to transmembrane translocation of four protons per electron pair (Richardson 2000), which would lead to 12 protons translocated per acetyl residue oxidized, and subsequent synthesis of 3-4 ATP. The energy span of this oxidation with menaquinone as acceptor is smaller. In fumarate reduction via menaquinone by $E$. coli (Unden and Bongaerts 1997), energy is conserved by a NADH-oxidizing proton-translocating dehydrogenase, but the stoichiometry of proton translocation in this reaction step is unknown. Known menaquinol:fumarate oxidoreductases do not translocate protons (Geisler et al. 1994; Iverson et al. 1999). Energy conservation in G. sulfurreducens during growth on acetate plus fumarate could be increased by consumption of eight protons on the cytoplasmic side of the membrane if this enzyme faces the cytoplasmic space, analogous to W. succinogenes (Geisler et al. 1994). An indication of this orientation has been obtained after partial membrane solubilization with CTAB.

If we assume that a Gibbs free energy change of about $-70 \mathrm{~kJ}$ is required to synthesize $1 \mathrm{~mol}$ ATP (Schink 1997), acetate oxidation to $\mathrm{CO}_{2}$ coupled to fumarate reduction $\left(\Delta G^{\circ}=-249 \mathrm{~kJ}\right.$ per mol acetate $)$ can yield ca. $3.6 \mathrm{~mol}$ ATP. An ATP yield of $10.0 \mathrm{~g}$ dry mass per mol ATP was calculated for growth on acetate in an inorganic salts medium (Stouthamer 1979). In our case, the ATP yield could be slightly higher because cysteine could contribute to a small extent to carbon assimilation. Thus, fumarate-dependent acetate oxidation allows the synthesis of 3-4 ATP via electron transport phosphorylation, but the proton translocation stoichiometry cannot yet be quantitatively assessed.

A comparison of enzyme activities (Table 3) proved that a complete citric acid cycle operates in G. sulfurreducens when acetate is oxidized in coculture with $W$. succinogenes (Fig. 2B). The 2-oxoglutarate:acceptor oxidoreductase detected in $W$. succinogenes presumably only operates in anabolic reactions (Bronder et al. 1982). Lack of sufficient hydrogenase or formate dehydrogenase activity indicated that neither hydrogen nor formate served as interspecies electron carrier to the partner bacterium.

Three of the electron pairs liberated in the citric acid cycle can reduce cytochrome(s) $c$ directly. Only electrons released in the succinate dehydrogenase reaction would need an ATP-dependent reversed electron transport (Table 4) to reduce cytochrome(s) $c$; perhaps menaquinone acts as electron carrier in this reaction chain. If a small cytochrome $c$ of a standard redox potential at $-167 \mathrm{mV}$ acts as major extracellular electron carrier (Seeliger et al. 1998), the standard free energy of acetate oxidation coupled to cytochrome $c$ reduction is $-95 \mathrm{~kJ}$ per mol acetate [calculated on the basis of the difference of the standard redox potentials of couples $\mathrm{CO}_{2}$ /acetate $(-291 \mathrm{mV})$ and oxidized/reduced cytochrome $c$ ]. This value allows synthesis of 1.4 ATP, resulting in $14 \mathrm{~g}$ cell dry mass produced per mol acetate dissimilated (calculated after Stouthamer
1979). The latter value matches the estimated cell yield of G. sulfurreducens in coculture with W. succinogenes $(14 \mathrm{~g}$ cell dry mass; Cord-Ruwisch et al. 1998). Thus, it appears reasonable that either the described cytochrome(s) or a carrier of similar redox potential transfers electrons between the two partners in this syntrophic association.

Our results indicate that both NADPH and NADH can transfer reducing equivalents to the electron transport chain during fumarate reduction by G. sulfurreducens. Similar results were obtained for $G$. metallireducens grown on benzoate plus $\mathrm{Fe}(\mathrm{III})$-citrate (Champine et al. 2000). Other authors reported that $\mathrm{Fe}(\mathrm{III})$ reduction in $G$. sulfurreducens depended strictly on NADH (Gaspard et al. 1998; Magnuson et al. 2000) and that the small cytochrome $c$ is not an efficient carrier of electrons to Fe(III) oxide (Lloyd et al. 1999). Further studies are required to elucidate the metabolic changes in the energy-conserving system of this bacterium during growth on acetate with $\mathrm{Fe}(\mathrm{III})$ as the electron acceptor.

Acknowledgement This study was supported by the Deutsche Forschungsgemeinschaft, Bonn-Bad Godesberg. The authors appreciate many helpful discussions with Jochen Müller, Konstanz.

\section{References}

Beh M, Strauss G, Huber R, Stetter K-O, Fuchs G (1993) Enzymes of the reductive citric acid cycle in the autotrophic eubacterium Aquifex pyrophilus and in the archaebacterium Thermoproteus neutrophilus. Arch Microbiol 160:306-311

Bergmeyer HU (1983) Methods of enzymatic analysis, vol I-III, Verlag Chemie, Weinheim, Germany

Brandis-Heep A, Gebhardt NA, Thauer RK, Widdel F, Pfennig N (1983) Anaerobic acetate oxidation to $\mathrm{CO}_{2}$ by Desulfobacter postgatei 1. Demonstration of all enzymes required for the operation of the citric acid cycle. Arch Microbiol 135:222-229

Bronder M, Mell H, Stupperich E, Kröger A (1982) Biosynthetic pathways of Vibrio succinogenes growing with fumarate as terminal electron acceptor and sole carbon source. Arch Microbiol 131:216-223

Caccavo FJR, Lonergan DJ, Lovley DR, Davis M, Stolz JF, McInerney MJ (1994) Geobacter sulfurreducens sp. nov., a hydrogen- and acetate-oxidizing dissimilatory metal-reducing microorganism. Appl Environ Microbiol 60:3752-3759

Champine JE, Goodwin S (1991) Acetate catabolism in the dissimilatory iron-reducing isolate GS-15. J Bacteriol 173:27042706

Champine JE, Underhill B, Johnston JM, Lilly WW, Goodwin S (2000) Electron transfer in the dissimilatory iron-reducing bacterium Geobacter metallireducens. Anaerobe 6:187-196

Chang D-E, Shin S, Rhee J-S, Pan J-G (1999) Acetate metabolism in a pta mutant of Escherichia coli W3110: importance of maintaining acetyl coenzyme A flux for growth and survival. J Bacteriol 181:6656-6663

Chohnan S, Furukawa H, Fujio T, Nishihara H, Takamura Y (1997) Changes in the size and composition of intracellular pools of nonesterified coenzyme A and coenzyme A thioesters in aerobic and facultatively anaerobic bacteria. Appl Environ Microbiol 63:553-560

Cord-Ruwisch R, Lovley DR, Schink B (1998) Growth of Geobacter sulfurreducens with acetate in syntrophic cooperation with hydrogen-oxidizing anaerobic partners. Appl Environ Microbiol 64:2232-2236 
Galouchko AS, Rozanova EP (1996) Sulfidogenic oxidation of acetate by a syntrophic association of anaerobic mesophilic bacteria. Microbiology (English translation Mikrobiologia) 65: 134-139

Gaspard S, Vazquez F, Holliger C (1998) Localization and solubilization of the Iron(III) reductase of Geobacter sulfurreducens. Appl Environ Microbiol 64:3188-3194

Gebhardt NA, Thauer RK, Linder D, Kauflers P-M, Pfennig N (1985) Mechanism of acetate oxidation to $\mathrm{CO}_{2}$ with elemental sulfur in Desulfuromonas acetoxidans. Arch Microbiol 141: 392-398

Geisler V, Ullmann R, Kröger A (1994) The direction of the proton exchange associated with the redox reactions of menaquinone during electron transport in Wolinella succinogenes. Biochim Biophys Acta 1184:219-226

Gottschalk G, Andreesen JR (1979) Energy metabolism in anaerobes. In: Quayle JR (ed) International review of biochemistry, microbial biochemistry, vol 21. University Park, Baltimore pp 85-115

Hattori S, Kamagata Y, Hanada S, Shoun H (2000) Theromoacetogenium phaeum gen., sp., a strictly anaerobic, thermophilic, syntrophic acetate-oxidizing bacterium. Int J Syst Evol Microbiol 50:1601-1609

Iverson TM, Luna-Chavez C, Cecchini G, Rees DC (1999) Structure of the Escherichia coli fumarate reductase respiratory complex. Science 284:1961-1966

Kluge C, Dimroth P (1993) Kinetics of inactivation of the $F_{1} F_{o}$ ATPase of Propionigenium modestum by dicyclohexylcarbodiimide in relationship to $\mathrm{H}^{+}$and $\mathrm{Na}^{+}$concentration: probing the binding site for the coupling ions. Biochemistry 32:1037810386

Kröger A, Geisler V, Lemma E, Theis F, Lenger R (1992) Bacterial fumarate respiration. Arch Microbiol 158:311-314

Lee MJ, Zinder SH (1988a) Hydrogen partial pressures in a thermophilic acetate-oxidizing methanogenic coculture. Appl Environ Microbiol 54:1457-1461

Lee MJ, Zinder SH (1988b) Isolation and characterization of a thermophilic bacterium which oxidizes acetate in syntrophic association with a methanogen and which grow acetogenically on $\mathrm{H}_{2}-\mathrm{CO}_{2}$. Appl Environ Microbiol 54:124-129

Lloyd JR, Blunt-Harris EL, Lovley DR (1999) The periplasmic 9.6-kilodalton c-type cytochrome of Geobacter sulfurreducens is not an electron shuttle to Fe(II). J Bacteriol 181:7647-7649

Magnuson TS, Hodges-Myerson AL, Lovley DR (2000) Characterization of a membrane-bound NADH-dependent $\mathrm{Fe}^{3+}$ reductase from the dissimilatory $\mathrm{Fe}^{3+}$-reducing bacterium Geobacter sulfurreducens. FEMS Microbiol Lett 185:205-211

Mikoulinskaia O, Akimenko V, Galouchko A, Thauer RK, Hedderich R (1999) Cytochrome $c$-dependent methacrylate reductase from Geobacter sulfurreducens AM-1. Eur J Biochem 263:346-352

Möller D, Schauder R, Fuchs G, Thauer RK (1987) Acetate oxidation to $\mathrm{CO}_{2}$ via a citric acid cycle involving an ATP-citrate lyase: a mechanism for the synthesis of ATP via substrate level phosphorylation in Desulfobacter postgatei growing on acetate and sulfate. Arch Microbiol 148:202-207

Paulsen J, Kröger A, Thauer RK (1986) ATP-driven succinate oxidation in the catabolism of Desulfuromonas acetoxidans. Arch Microbiol 144:78-83

Pealing SL, Black AC, Manson FD, Ward FB, Chapman SK, Reid GA (1992) Sequence of the gene encoding flavocytochrome $c$ from Shewanella putrefaciens: a tetraheme flavoenzyme that is a soluble fumarate reductase related to the membrane-bound enzymes from other bacteria. Biochemistry 31:12132-12140
Ragsdale SW (1991) Enzymology of acetyl-CoA pathway of $\mathrm{CO}_{2}$ fixation. Crit Rev Biochem Mol Biol 26:261-300

Richardson DJ (2000) Bacterial respiration: a flexible process for a changing environment. Microbiology 146:551-571

Rothery RA, Weiner JH (1998) Interaction of a menaquinol binding site with the (3Fe-4S) cluster of Escherichia coli fumarate reductase. Eur J Biochem 254:588-595

Schink B (1997) Energetics of syntrophic cooperation in methanogenic degradation. Microbiol Mol Biol Rev 61:262280

Schmitz RA, Bonch-Osmolovskaya EA, Thauer RK (1990) Different mechanisms of acetate activation in Desulfurella acetivorans and Desulfuromonas acetoxidans. Arch Microbiol 154: 274-279

Schnürer A, Houwen FH, Svensson BH (1994) Mesophilic syntrophic acetate oxidation during methane formation by a triculture at high ammonium concentrations. Arch Microbiol 162: 70-74

Schnürer A, Schink B, Svensson BH (1996) Clostridium ultunense sp. nov., a mesophilic bacterium oxidizing acetate in syntrophic association with a hydrogenotrophic methanogenic bacterium. Int J Syst Bacteriol 46:1145-1152

Schnürer A, Svensson BH, Schink B (1997) Enzyme activities in and energetics of acetate metabolism by the mesophilic syntrophically acetate-oxidizing anaerobe Clostridium ultunense. FEMS Microbiol Lett 154:331-336

Seeliger S, Cord-Ruwisch R, Schink B (1998) A periplasmic and extracellular $c$-type cytochrome of Geobacter sulfurreducens acts as a ferric iron reductase and as an electron carrier to other acceptors or to partner bacteria. J Bacteriol 180:3686-3691

Shestopalov AI, Bogachev AV, Murtazina RA, Viryasov MB, Skulachev VP (1997) Aeration-dependent changes in composition of the quinone pool in Escherichia coli. Evidence of posttranscriptional regulation of the quinone biosynthesis. FEBS Letters 404:272-274

Stams AJM, Kremer DR, Nicolay K, Weenk GH, Hansen TA (1984) Pathway of propionate formation in Desulfobulbus propionicus. Arch Microbiol 139:167-173

Stouthamer AH (1979) The search for correlation between theoretical and experimental growth yields. In: Quayle JR (ed) International review of biochemistry, microbial biochemistry, vol 21. University Park, Baltimore, pp 1-47

Thauer RK (1988) Citric-acid cycle, 50 years on. Modifications and an alternative pathway in anaerobic bacteria. Eur J Biochem 176:497-508

Thauer RK, Jungermann K, Decker K (1977) Energy conservation in chemotrophic anaerobic bacteria. Bacteriol Rev 41:100-180

Voegele RT, Mitsch MJ, Finan TM (1999) Characterization of two members of a novel malic enzyme class. Biochim Biophys Acta 1432:275-285

Unden G, Bongaerts J (1997) Alternative respiratory pathways of Escherichia coli: energetics and transcriptional regulation in response to electron acceptors. Biochim Biophys Acta 1320: 217-234

Zeikus JG, Fuchs G, Kenealy W, Thauer RK (1977) Oxidoreductases involved in cell carbon synthesis of Methanobacterium thermoautrophicum. J Bacteriol 132:604-613

Zinder SH, Koch M (1984) Non-acetoclastic methanogenesis from acetate: acetate oxidation by a thermophilic syntrophic coculture. Arch Microbiol 138:263-272 